Arroyo, P., Schöttle, A. Christensen, R., Alves, T., Bastos Costa, D., Parrish, K. and Tsao, C. (2018). "Impact of gender bias on career development \& work engagement in the OAEC industry \& lean practice" In: Proc. $26^{\text {th }}$ Annual Conference of the International. Group for Lean Construction (IGLC), González, V.A. (ed.), Chennai, India, pp. 442-451. DOI: doi.org/10.24928/2018/0496. Available at: www.iglc.net

\title{
IMPACT OF GENDER BIAS ON CAREER DEVELOPMENT \&WORK ENGAGEMENT IN THE OAEC INDUSTRY \& LEAN PRACTICE
}

\author{
Paz Arroyo ${ }^{1}$, Annett Schöttle ${ }^{2}$, Randi Christensen ${ }^{3}$, Thais Alves ${ }^{4}$, \\ Dayana Bastos Costa ${ }^{5}$, Kristen Parrish ${ }^{6}$, and Cynthia Tsao ${ }^{7}$
}

\begin{abstract}
This paper examines findings from a gender bias study in the Owner, Architecture, Engineering, and Construction (OAEC) industry. By definition, a bias is a deviation from what is normal, which is defined by social norms. If different attitudes towards male vs. female co-workers exist, then one group may gain subtle yet impactful advantages in career development and work engagement. To what extent does this happen within the OAEC industry, including lean construction practice? While several industries studied the negative impact of gender bias on women in the workplace, this has not been studied in the lean construction community. Thus, this study fills the gap. Lean is based on respect for people and continuous improvement. Do these principles translate into more equitable experiences in promoting ideas, and in career development and work engagement for men and women in the OAEC industry? Regardless, if gender biases are acknowledged, then what programs exist or might exist to provide support to the disadvantaged group and level the playing field? The authors addressed these questions by administering a survey over social networks. This paper highlights initial results to raise awareness of the existence and impact of gender bias and begin exploring methods to overcome it.
\end{abstract}

\section{KEYWORDS}

Gender Bias, Career Development, Work Engagement, Lean, Respect, Change Management

Asst.Prof., Catholic University of Chile parroyo@ing.puc.cl; Senior Coach, Lean Project Consulting, USA, parroyo@leanproject.com

Senior Consultant, Refine Projects AG, GER, annett.schoettle@ refineprojects.com

Lean Manager, Lower Thames Crossing, COWI, UK, RMCH@ cowi.com

Associate Prof., CCEE Dept., San Diego State Univ., USA, talves@ mail.sdsu.edu

Associate Prof., PPEC Program, Fed. Univ. of Bahia, Brazil, dayanabcosta@ufba.br

Asst.Prof., DEW School of Constr., Arizona State U., USA, Kristen.Parrish@asu.edu

Dir. Lean Strategy, Consigli Constr. Co.; Owner, Navilean, research@navilean.com 
Impact of Gender Bias on Career Development \&

\section{INTRODUCTION}

A bias by definition is a deviation from what is normal, where "normal" is defined according to social norms. Bias can be conscious or unconscious, and it may manifest in subtle or obvious ways (d'Orgeville et al. 2014). The term "gender bias" is a preference toward or prejudice against one gender over the other. McLoughlin (2005) identifies three types of biases towards women: Type I is singling out with the intention to harm (overt sexism); Type II is doing so with neutral intentions (tacit sexism); and Type III, a new type of gender bias, is singling out women with the intention to help them. According to d'Orgeville et al. (2014), "the vast majority of gender-related issues in [Science, Technology, Engineering, and Mathmatics]STEM fields arise from the fact that many men and women were raised, educated and became STEM professionals in traditionally male-dominated societies." They explain that a male-dominated culture is evident throughout society, and it is often cited as why females are rarely represented at the level they should be based on their numbers alone.

Multiple studies document gender bias in STEM education (e.g., PCAST 2012; Menches and Abraham 2007; del Puerto et al. 2011) and workplaces (e.g., Slaughter 2012; Sandberg 2013). This paper focuses on the Owner, Architecture, Engineering and Construction (OAEC) industry, where relatively less work has been done. The OAEC industry is male-dominated; men occupy most of the top positions in OAEC organizations. According to Chun et al. (2009), women are reluctant to join the OAEC workforce as they experience discrimination when they apply for a job or when they join the workforce. Chun et al (2009) conducted a survey to evaluate perceptions of women in construction management (CM) positions and found that, "Female construction managers (CMs) perceive bias against them in the form of scepticism and indifference as a response to their gender." They also explain that most respondents believe female CMs are as effective as male CMs and the authors hypothesized that negative perceptions relative to women would dissipate as more women filled the CM workforce.

Gender bias seems contradictory to lean, which is based on the principles of respect for people and continuous improvement. As a result, this paper explores the extent of gender bias within the OAEC industry and specifically, within lean construction practice. The removal of gender bias barriers will, ultimately, result in organizations gaining a competitive advantage in today's global markets (Maskell-Pretz et al. 1997). Thus, in addition to exploring the extent in which gender bias impacts career development and work engagement, the authors also explore how OAEC organizations are working to combat gender bias. The balance of this paper presents survey methods and results and closes with conclusions that serve as a foundation for future research and discussion.

\section{RESEARCH QUESTIONS AND METHOD}

This paper seeks to address the following questions: Does gender bias exist in the OAEC industry? How does gender bias impact recruitment and promotion? How does gender bias impact work engagement? and Do lean principles translate into more equitable experiences in career development and work engagement via lean construction practice? 
The authors used a survey as the research method to answer these questions, distributed the survey over professional networks (e.g., LinkedIn, Facebook, Xing, and email), and received answers from both men and women working in the OAEC industry.

The survey consisted of 19 questions grouped into five sections: (1) general information of the respondent and overall perspective on gender bias; (2) recruitment process; (3) promotion process; (4) work engagement via the reception to new ideas; and (5) programs in organizations to overcome gender bias. The authors analysed survey results in two ways - multiple-choice questions with yes/no answers and likert scale responses summarized using frequencies. Then, we summarized and generalized open questions, which is a method frequently used in Social Science (e.g., Mayring 2014).

\section{RESULTS}

Of the 153 survey responses, the authors removed one respondent who was not a part of the OAEC industry. Of the remaining 152 valid responses, 53\% were women and $47 \%$ were men. $65 \%$ of the men and $44 \%$ of women reported being a parent.

In terms of OAEC industry experience, 8 respondents had less than 2 years, 26 had 2 to less than 5 years, 30 had5 to less than 10 years, 47 had 10 to less than 20 years, and 41 had more than 20 years. Survey respondents represented several countries: 46 from US; 29 from UK; 17 from Spain; 16 from Denmark; 11 from Germany; 4 each from Canada, Chile, and Brazil; 3 each from Finland and Ireland; 2 each from Australia, Mexico, and Norway; and 1 each from Argentina, Austria, Cameroon, Ecuador, Estonia, Greece, Hong Kong, Iran, and Israel.

The authors recognize that this is not a statistically representative sample of the OAEC industry. However, the participation of respondents from different levels of experience and geographical areas represent a diverse pool of professionals that provide some important conclusions and discussions about the questions being asked.

\section{GENERAL PERCEPTION ON GENDER BIAS}

The results show that $75 \%$ of women vs. $62 \%$ of men feel positively affected by their gender, but only $13 \%$ of women vs. $27 \%$ of men frequently or very frequently feel positively affected by their gender(Figures 1 and 2).

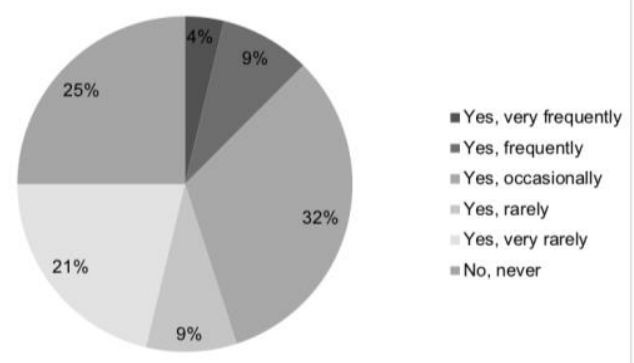

Figure 1: \% of women who feel positively affected by their gender

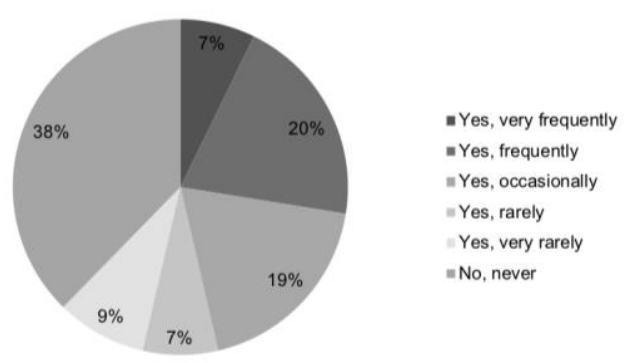

Figure 2: \% of men who feel positively affected by their gender

In contrast, $89 \%$ of women vs. $21 \%$ of men feel negatively affected by their gender, and $32 \%$ of women vs. $0 \%$ of men frequently or very frequently feel negatively affected 
by their gender (Figures 3 and 4). These results demonstrate that women feel the negative and positive effects of their gender more often than their male colleagues.

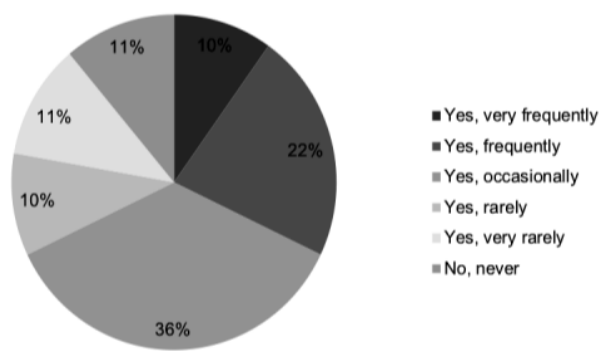

Figure 3: \% of women who feel negatively affected by their gender

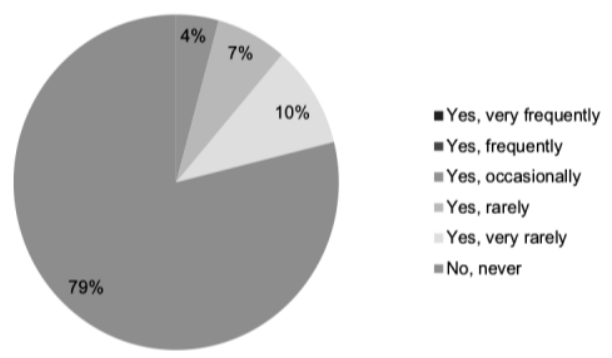

Figure 4: \% of men who feel negatively affected by their gender

\section{LEAN EXPERIENCE OF SURVEY RESPONDENTS}

Since the authors specialize in lean research and practice, and we reached out to our professional networks to recruit survey respondents, half of all survey respondents have significant lean experience in their jobs (28\% report implementing lean tools and methods very frequently and $22 \%$ report implementing them frequently). There is no significant difference between genders in terms of lean experience: $47 \%$ of women vs. $52 \%$ of men reported working in a lean environment.

\section{IMPACT OF GENDER BIAS ON CAREER DEVELOPMENT}

\section{Recruitment Process}

About $16 \%$ of all survey respondents reported experiencing rejection in a recruitment process because of gender bias. When broken down by gender, $26 \%$ of women vs. $4 \%$ of men reported experiencing rejection in a recruitment process because of gender bias. This indicates that women are 6 times more likely to be rejected during recruitment because of their gender compared to men.

When asked for specific examples that illustrate rejection during recruitment, respondents provided more insights about this issue. The only male recruitment rejection example emerged when one male respondent noted that women are preferred for office roles, so he experienced problems when he applied to one of those positions. In contrast, female recruitment rejection examples ranged from directly receiving inappropriate comments such as "This is not a job for women," to more subtle questions (or microaggressions) about plans to have children. Other female respondents reported being unsure about whether they were not selected due to being a woman. Quotes that highlight these perspectives include:

- "In 1975 I was told being a female was a disadvantage and again in 1982 but not since then"

- "Passed over frequently for less qualified males, penalized for things beyond my control or that were the fault of a male"

- "When much younger, I had direct questions from an interviewer about why a woman would want to be an engineer - and was then hired for the job. At another 
Paz Arroyo, Annett Schöttle, Randi Christensen, Thais Alves,

Dayana Bastos Costa, Kristen Parrish, and Cynthia Tsao

firm, the principal never sent me [to a] construction site job because he didn't think the foremen would treat me with respect / implement my recommendations"

- "I'm not sure if it happens to me but I believe in the recruitment process, the possibility of being [a] mother [doesn't] help us to 'open doors' to a new opportunity of a job"

- "I've been asked always about maternity, if I was thinking about having children, I was warned about the maternity leave of the company. When I said I wanted to be on site, I was told this was so hard for a woman"

- "I was qualified for the position I was applying, however, a male potential worker was employed"

\section{Promotion Process}

$17 \%$ of all survey respondents reported being delayed in a promotion due to gender bias. When broken down by gender, $32 \%$ of women vs. $0 \%$ of men reported being delayed in a promotion due to gender bias. In other words, one-third of female respondents experienced promotion delays due to gender bias, and only women experienced being delayed in a promotion due to gender bias.

Specific promotion delay examples include: seeing less qualified male colleagues get promotions before them, differences in salary found by chance, reluctance to give titles/positions of power to women doing the same job as men, and some women who are not sure they have experienced promotion delays due to a hidden evaluation process. Quotes that highlight these cases and reinforce the existence of gender bias include:

- "I had more experience than an older male colleague but due to his age and sex was told that I couldn't go higher than him. My female line manager told me this."

- "I was one of two graduates from [the same university] hired for the same role, with the same experience. The male candidate was offered $\$ 5000$ more than me annually."

- "Possibly. It's hard to know for sure what the reasons are when you don't get a promotion as quickly as expected"

- "Non-licensed individuals were promoted before me, a licensed individual"

- "They do not tell it straight, but all the guys played golf or football with the bosses, became friends and got the promotion thanks to becoming sport mates, they increased their profile and possibilities."

- "In the 1990s, I was leading a team of estimators, but was never given the title Chief Estimator. As soon as I left the company, the man I had trained was named Chief Estimator.

- "I strongly believe that my male co-workers were promoted before me and make more money than me."

- "As a female, I am super conscientious and will work the hours needed to complete the work, and not complain about the pay. Management takes advantage of this, as I have seen less hard-working men promoted and given."

- "There is a guy in my company who is 10 years younger, has really much less knowledge and no special expertise, but has the same position as I do." 


\section{IMPACT OF GENDER BIAS ON WORK ENGAGEMENT}

According to Schaufeli et al. (2002), "a positive, fulfilling, work-related state of mind that is characterized by vigor, dedication, and absorption". As a result, to begin investigating the impact of gender bias on work engagement, the survey asked respondents if they had ever experienced the sensation that their ideas were not taken that seriously because of their gender.

$36 \%$ of all survey respondents reported experiencing the sensation that their ideas were not taken that seriously because of their gender (Table 1). When broken down by gender, $62 \%$ of women vs. $4 \%$ of men reported experiencing the sensation that their ideas were not taken that seriously because of their gender.

Dueto this stark contrast, we then evaluated the results according to the intensity in which the respondents were involved in lean practice. Earlier, we noted that $28 \%$ of respondents reported implementing lean tools and methods very frequently and $22 \%$ reported implementing them frequently. We characterize these respondents as "Intense Lean" practitioners vs. those that are not (including respondents that reported implementing lean tools and methods occasionally, rarely, very rarely, and never).

Might these intense lean respondents encounter less rejection of their ideas because they were working within a lean environment that would prioritize respect for people and continuous improvement? Or would these intense lean respondents instead encounter more rejection of their ideas since respondents that implement lean very frequently and frequently tend to be involved in the role of a change agent, so there is a higher likelihood that their ideas involve asking their co-workers to try a different approach or method for completing a specific work task but their co-workers remain resistant to change?Yet another facet to consider - are intense lean respondents more observant of their coworkers actions, comments, and moods during meetings or work sessions (Flores 2016) and thus be more attuned to the subtle sensation that their ideas were not taken that seriously because of their gender?

The results revealed $39 \%$ of intense lean respondents vs. $32 \%$ of non-intense lean respondents reported experiencing the sensation that their ideas were not taken that seriously because of their gender (Table 1).

Table 1: Respondents that experienced the sensation that their ideas were not taken that seriously because of their gender (according to gender or intensity in lean practice)

\begin{tabular}{cccccc}
\hline $\begin{array}{c}\text { Ideas not taken } \\
\text { seriously }\end{array}$ & All & Women & Men & Intense Lean & $\begin{array}{c}\text { Non-Intense } \\
\text { Lean }\end{array}$ \\
\hline Yes & 54 & 51 & 3 & 29 & 25 \\
No & 98 & 30 & 68 & 46 & 52 \\
Yes [\%] & $36 \%$ & $62 \%$ & $4 \%$ & $39 \%$ & $32 \%$ \\
\hline
\end{tabular}

Thus, while the gender of respondents had a major correlation to the likelihood they would report experiencing the sensation that their ideas were not taken that seriously because of their gender ( $62 \%$ of women vs. $4 \%$ of men), the intensity in which the respondents were involved in lean practice only had a minor correlation (39\% of intense 
lean respondents vs. $32 \%$ of non-intense lean respondents). Table 2 breaks down the analysis further to help reveal additional insights.

Table 2: Respondents that experienced the sensation that their ideas were not taken that seriously because of their gender (according to gender + intensity in lean practice)

\begin{tabular}{cccccc}
\hline $\begin{array}{c}\text { Ideas not taken } \\
\text { seriously }\end{array}$ & All & $\begin{array}{c}\text { Women + } \\
\text { Intense Lean }\end{array}$ & $\begin{array}{c}\text { Women + Non- } \\
\text { Intense }\end{array}$ & $\begin{array}{c}\text { Men + Intense } \\
\text { Lean }\end{array}$ & $\begin{array}{c}\text { Men + Non- } \\
\text { Intense Lean }\end{array}$ \\
\hline Yes & 54 & 27 & 24 & 2 & 1 \\
No & 98 & 11 & 19 & 35 & 33 \\
Yes [\%] & $36 \%$ & $71 \%$ & $56 \%$ & $5 \%$ & $3 \%$ \\
\hline
\end{tabular}

Table 1 and 2 reveals: (1) Compared to their male colleagues, women are 17 times more likely to experience that their ideas are not taken that seriously,(2) Compared to their intense lean male colleagues, intense lean women are 13.5 times more likely to experience that their ideas are not taken that seriously,(3) Compared to their non-intense lean male colleagues, non-intense lean women are 24 times more likely to experience that their ideas are not taken that seriously.

Even though this survey is addressing the respondents' perceptions, and there is no plausible way to verify every claim made, it is alarming that $62 \%$ of women feel that their contributions are not taken seriously and this value increases to $71 \%$ for women involved in intense lean practice. This finding might be related to a recent study indicating that in departmental talks with roughly the same amount of men and women attending, men ask 2.5 times more questions when compared to the women attending these events, and they also usually ask the first question. The difference in the number of questions asked by people from both genders disappears when a woman asks the first question and other women follow suit (The Economist 2017).

In total, 42 women (52\%) provided examples of occasions when their ideas were not taken that seriously because of gender. Most respondents claimed that their male colleagues are not listening to /are ignoring them, they are not taken seriously / are discounted, interrupted /spoken over, their male colleagues are repeating their ideas and being supported, and got the recognition for the idea.

\section{PROGRAMS TO COMBAT GENDER BIAS}

About a third of respondents stated that their organizations have a program to address gender bias, whereas two-thirds do not have such a program. The majority of programs reported were sessions for raising awareness about gender bias (34), mentoring (22), supporting colleagues (22), and coaching (10).

Women reported that programs that have worked for them in the past consisted of sessions raising gender bias awareness for men (12) and mentoring by males or females (10). Another large portion of respondents decided to address the problem of gender bias by working harder than men (5).

In terms of programs that respondents wished their organization implemented, both women and men proposed having sessions or conversations more frequently to raise 
Impact of Gender Bias on Career Development \& Work Engagement in the OAEC Industry \& Lean Practice

awareness and establishing a more transparent and fair processes for hiring and promoting individuals. In addition, it was interesting to note that 10 men and three women stated that these types of programs were not needed, and several men answered, "Do not know." Some insights on gender bias programs from women include:

- "I don't want programs, I just want it to be naturally ingrained in the daily work life. If something happens to me personally, I make sure to point it out to the offender(s)"

- "Talking openly about it (diversity) and ensuring there is an understanding from seniors that we are all equal"

- "More awareness for male colleagues. If the men we work with aren't aware of the issue, it's challenging for them to make corrections"

- "To oblige organizations to hire the same quantity and in the same conditions both men and women (gender equality)"

- "Human Resource selection process without names, photos, age..."

- "Programmes are not necessarily the answer, it's about changing behaviours"

Examples of programs that men wish to have to deal with gender bias:

- "Actions to overcome gender bias should start with the organisation identifying the extent to which employees feel affected by it, including details of why they feel that way, under what circumstances and how often. Running awareness sessions without first identifying these details could limit the intended positive impact."

- "Raising awareness, education and discussion, should be more prominent in our organisation. This includes understanding a woman's perspective on the OAEC. IE what are the real issues that still need to be addressed and the perceptions that also stop women pursuing a career in OAEC. In our organisation, there is far too much of a bias in management towards men, to change this bias does require some positive action and a strategy agreed to achieve positive action."

- "Equal salaries for equal jobs."

- "This is very much a male dominated sector with an embedded culture. It will take time for females to be accepted into traditional male roles especially on site teams."

\section{DISCUSSION}

The survey respondents comprised of women (53\%) and men (47\%) representing 22 countries, and about half of the respondents implement lean in some form with varying degrees of intensity. By any measure, women perceive that their gender affects them negatively more often than their male colleagues and that is substantiated by other findings of this study. Female respondents in this population were six times more likely than male respondents to experience rejection in recruitment, and a third of them indicated that they experienced delays in the promotion processes due to their gender. Moreover, when it comes to sharing ideas, two-thirds of female respondents indicated that their ideas are not taken seriously, and in some cases, they report that these ideas are not taken seriously until a male co-worker proposes the same ideas or explainsit. Most female respondents report that they feel their ideas are ignored within the OAEC 
community, and this represents an important and urgent area for improvement. This discussion becomes even more timely and relevant within the Lean community when we consider that lean promotes respect for people and shared values and goals to promote continuous improvement. In a Lean environment, all should be respected for their ideas and contributions and feel safe and encouraged to share their thoughts.

Several people were aware of gender bias as an issue, however there is no consensus about how to fix the problem. Perhaps lean principles and tools can help with providing more transparency in the hiring and promotion processes. Future research is needed to understand how, for example, a more transparent and fair decision-making process such Choosing By Advantages could help beyond its current applications (Arroyo et al., 2016). In terms of promoting women's ideas, it is important to acknowledge that most of the examples given are perceptions, which may or may not be grounded in reality; these do not necessarily represent facts (Flores 2016). However, these perceptions of women's capabilities may be understood by men and women as facts, and may, in turn, be limiting career advancement opportunities for women. In addition, many men and women present a mood of resignation about the state of gender in the OAEC Industry, which inhibits a learning predisposition that is required to affect change (Flores 2016). Finally, categorically dismissing the ideas of any portion of the workforce, in this case, women, seems a poor strategy for continuous improvement; indeed, such behaviour limits the possibility of implementing lean principles.

\section{CONCLUSION}

The results of this study show women and men perceive gender bias in the OAEC industry. Often, this bias seems to negatively impact the working lives of women. Women perceive their gender as a reason to not be recruited or be delayed in promotion; women report (with alarming frequency) experiencing gender bias when sharing ideas.

Women that reported having implemented lean with higher frequency actually reported a higher percentage of their ideas not being taken seriously due to gender bias, this was counterintuitive to the researchers. Respondents might be in an environment that seems welcoming to new ideas; however, this study illustrates that regardless of lean implementation, women feel their ideas are not heard. This suggests that despite a "lean" culture promoted in some OAEC organizations, women do not feel heard.

Female respondents present more negative perceptions about gender bias and how this affects their work lives. Whether these perceptions are supported with evidence or not, which was not part of the scope of this research, these negative perceptions influence what women in the OAEC Industry think is possible or not in terms of career advancement and the pursuit of their ideas. Most male respondents recognize or observe gender bias in the OAEC Industry. Paradoxically, a larger portion of men compared to women think that gender bias is not an issue, and no programs or strategies are necessary for correction. However, the majority of men and women explicitly wish to have better programs or deliberate actions to overcome gender bias in the OAEC Industry. The most often suggested intervention is to raise awareness, and have more open conversations to share perceptions of gender bias. 
Impact of Gender Bias on Career Development \&

More research is needed to understand how to implement interventions and programs to overcome gender bias. Further, the authors plan to conduct statistical analysis of the survey data to determine if any of the trends reported herein show statistical significance.

\section{ACKNOWLEDGEMENTS}

We would like to thank all survey respondents as well as those who helped us distribute this survey to a broader audience.

\section{REFERENCES}

Arroyo, P., Fuenzalida, C., Alberti, A., Hallowell, M. (2016) "Collaborating in Decision Making of SustainableBuilding Design: An Experimental Study Comparing CBA and WRC Methods" Energy and Buildings, 128, pp.132-142.

Anderson, L. and Gilbride, K. (2007). Gender Bias Towards Engineering Careers: Does It Still Exist?. Women in Engineering ProActive Network.

Chun, B.L., Arditi, D. and Balci, G., 2009. Women in construction management. CMAA eJournal.

del Puerto, C. L., Guggemos, A. A., and Shane, J. (2011). "Exploration of Strategies for Attracting and Retaining Female Construction Management Students." Proc. 47th ASC Annual International Conference, $8 \mathrm{pp}$.

d'Orgeville, C., Rigaut, F., Maddison, S. and Masciadri, E. (2014). Gender equity issues in astronomy: Facts, fiction, and what the adaptive optics community can do to close the gap. In:Adaptive Optics Systems IV (Vol. 9148, p. 91481V). International Society for Optics and Photonics.

Flores, G. (2016). Learning to Learn and the Navigation of Moods: The Meta-Skill for the Acquisition of Skills.Pluralistic Networks Publishing.

Maskell-Pretz, M. and Hopkins, W.E. (1997). Women in engineering: Toward a barrierfree work environment. Journal of Management in Engineering, 13(1), 32-37.

Mayring,P. (2014).Qualitative content analysis: Theoretical foundation, basic procedures and software solution. SSOAR, Klagenfurt.

McLoughlin, L.A. (2005). "Spotlighting: Emergent gender bias in undergraduate engineering education."Journal of Engineering Education, 94(4), 373-381.

Menches, C.L., and Abraham, D.M. (2007). "Women in Construction-Tapping the Untapped Resource to Meet Future Demands.” J. Constr. Eng. Manage., 133(9), 701707.

Sandberg, S. (2013). Lean In: Women, Work, and the Will to Lead, Knopf, 240 pp.

Schaufeli, W.B., Salanova, M., González-Romá, V., and Bakker, A. B. (2002). "The measurement of engagement and burnout."Journal of Happiness Studies, 3, 71-92.

Slaughter, A.M. (2012). "Why Women Still Can’t Have It All.” Atlantic,July, 85-102.

The Economist (2017). Women ask fewer questions than men at seminars. 12/07/2017. Available at: https://tinyurl.com/yapfznp3. 